\title{
Enhancing the research experience through peer-reviewed literature
}

\author{
Prashant Mahajan
}

Received: 9 July 2008 / Accepted: 18 July 2008 / Published online: 22 August 2008

(C) Springer-Verlag London Ltd 2008

\section{Dear Editors,}

Your article "Clinical research 101: Why should you care?" [1] was very interesting and I applaud the journal, which in its infancy is addressing issues such as importance of clinical research. As you correctly mention, the emergency department (ED) is a clinical laboratory, and clinical research apart from answering some of the most pertinent questions has the additional value of being immediately relevant to patient care. As a research director of a very busy pediatric ED with an active fellowship in pediatric emergency medicine, I am constantly struggling to convey the message that research is not an entity which gets conducted solely in laboratories or demands extensive knowledge of statistics to my colleagues. Research is a very important step in improving patient care by applying what is known to the patient immediately in front of you. Research provides the foundation for evidencebased medicine and the tools for evidence-based practice. I would also add that research can vary in its quality and comprehensiveness. Practitioners of emergency medicine must be discerning enough to critically appraise research as there are many instances of "published" studies that either lack the appropriate methodology, adequate sample size, or rigorous analysis. Additionally, research is constantly evolving and what is considered as gospel may be eventually refuted with a well-conducted study. Use of steroids in

P. Mahajan $(\square)$

Pediatric Emergency Medicine, Carman \& Ann Adams

Department of Pediatrics, Children's Hospital of Michigan,

Detroit, MI 48201, USA

e-mail: pmahajan@dmc.org bronchiolitis is an example. A well-conducted doubleblinded randomized controlled trial $(n=70)$ performed at one ED comparing a single dose of oral dexamethasone with a placebo in children with moderate to severe bronchiolitis showed a substantial reduction in hospitalization along with clinical improvement. This study was powered to detect a difference in a clinical score not rates of hospitalization [2]. Yet, using these efficacy data, many practitioners changed their practice and started using oral dexamethasone in the management of bronchiolitis. A subsequent larger, multicenter study (effectiveness study) showed no effect of a single dose of oral dexamethasone when the study was powered to detect a $12 \%$ difference in admission rates $(n=600)$. This second study clearly showed that there was no difference in hospitalization rates [3]. The challenge now is to disseminate these findings - translating research into practice (TRIP).

In conclusion, I think it is important for journals such as yours to enhance the research experience by (a) publishing articles on research methodology, (b) being more discerning as to which articles get accepted, and (c) broadening the scope of emergency research by publishing articles on research ethics in varied settings, i.e., international emergency medicine.

\section{References}

1. Stead LG, Decker WW (2008) Clinical research 101: why should you care? Int J Emerg Med 1:121-122 doi:10.1007/s12245-0080035-1

2. Schuh S, Coates AL, Binnie R et al (2002) Efficacy of oral dexamethasone in outpatients with acute bronchiolitis. J Pediatr 140(1):27-32

3. Corneli HM, Zorc JJ, Mahajan P et al (2007) A multicenter, randomized, controlled trial of dexamethasone for bronchiolitis. $\mathrm{N}$ Engl J Med 357(4):331-339 